Gut, 1971, 12, 830-834

\title{
Portal hypertension in primary biliary cirrhosis
}

\author{
M. C. KEW, ${ }^{1}$ R. R. VARMA, H. A. DOS SANTOS, P. J. SCHEUER, AND \\ SHEILA SHERLOCK
}

From the Departments of Medicine and Pathology, The Royal Free Hospital, London

SUMMARY Evidence of portal hypertension was found in 50 out of 109 patients $(47 \%)$ with primary biliary cirrhosis, and of these 32 bled from oesophageal varices. In four patients portal hypertension was the initial manifestation of the disease and this complication was recognized in a further 17 within two years of the first symptom of primary biliary cirrhosis. The development of portal hypertension was associated with a poor prognosis and death could frequently be attributed to variceal bleeding; the mean duration of survival from the time that portal hypertension was recognized was 14.9 months. Portal decompression operations may have improved the immediate prognosis in some patients but did not otherwise influence the progression of the disease. In 47 patients the histological findings in wedge biopsy or necropsy material were correlated with the presence or absence of varices. An association between nodular regeneration of the liver and varices was confirmed, but, in the absence of nodules, no other histological cause for portal venous obstruction could be found.

Bleeding from oesophageal varices has been thought to be a late and infrequent complication of primary biliary cirrhosis (Sherlock, 1959; Rubin, Schaffner, and Popper, 1965). However, in a recent report by Zeegen, Stansfeld, Dawson, and Hunt (1969), the initial complaint in 15 out of 23 patients with this disease who required portal decompression surgery was variceal haemorrhage. This mode of presentation was confirmed by Sicot and Benhamou (1970) who noted that portal hypertension may develop at any stage in the course of the disease. Although their observations were based on a small number of cases, they felt that this complication occurred more commonly than had previously been thought. The prevalence of portal hypertension and the stage at which it develops has, however, not been established in a large sories of unselected patients with primary biliary cirrhosis. Moreover, although it has been shown that the presence of portal hypertension does not necessarily correlate with the histological finding of nodular regeneration of the liver (Sherlock, 1959; Hoffbauer, 1960; Zeegen et al, 1969; Sicot and Benhamou, 1970), a detailed correlation with other histological features which might possibly be incriminated in the pathogenesis of portal hypertension has not been reported.

'Wellcome research fellow.

Received for publication 21 July 1971.

\section{Material and Methods}

One hundred and nine patients seen at the Royal Free Hospital between 1960 and 1970 were included in the study. The diagnosis of primary biliary cirrhosis was made on the basis of the clinical features and biochemical findings (Sherlock, 1959), and confirmed in 83 cases by finding mitochondrial antibodies in the serum and histological changes in the liver which were typical of or compatible with this disease (Rubin et al, 1965). Mitochondrial antibodies could not be demonstrated in the serum of three patients and were not looked for in the remaining 23; they were included in the study because, in addition to showing typical clinical and biochemical features, the histological changes were considered to be unequivocal. Extrahepatic biliary obstruction was excluded at laparotomy in 52 patients and at necropsy in a further 15 . The group comprised 100 women and nine men with a mean age at the time of diagnosis of 51.9 years (range 29-81 years). The mean time elapsing from the onset of symptoms to death or until the patients were last seen was 62.6 months (range 1-195 months). Forty-one (37.6\%) of the patients have died; the mean duration of survival from the onset of illness was 73.9 months (range 7-163 months). The characteristics of the patients in the group as a whole are thus similar to 
those previously reported (Sherlock, 1959; Rubin et al, 1965).

Since barium studies were available in all patients, the diagnosis of portal hypertension was based on the radiological demonstration of oesophageal varices. This, in association with an enlarged spleen with or without ascites, is strong presumptive evidence of portal hypertension. The presence of splenomegaly and ascites was not taken as evidence of portal hypertension in the absence of varices. In 12 patients with varices splenic pulp pressures were measured at the time of portal venography. These were always elevated.

The time of onset of symptoms, diagnosis of primary biliary cirrhosis, and first recognition of oesophageal varices was recorded in each patient together with the relevant clinical findings, biochemical data (serum bilirubin, alkaline phosphatase, cholesterol, and aspartate transaminase levels) and final outcome. When a portal decompression operation, oesophageal or gastric transection, or ligation of varices was performed, the time and outcome were noted. Operative wedge biopsies or necropsy material were available for detailed histological study in 47 patients. Of these, 26 showed clinical and radiological evidence of portal hypertension at the time the histological material was obtained (at portocaval anastomosis in 11, exploratory laparotomy in 13, and necropsy in two). The remaining patients did not have varices at the time liver tissue was obtained (at exploratory laparotomy in 19 and necropsy in two) and they served as a control group. The histological material was studied by two of the authors independently and without knowing whether or not varices were present.

The following were noted and assessed semiquantitatively: nodular regeneration, portal fibrosis, cellular infiltration, and lymphoid aggregates in the portal tracts and septa, number of arterioles and thickness of arteriolar walls and number of thinwalled vessels in the portal tracts, number and size of efferent veins, width of sinusoids, degree of mononuclear cell infiltration of sinusoids, hyperplasia or prominence of the Kupffer cells, and a consistent increase in the number of twin-hepatocyte plates.
No attempt was made to differentiate between venules and lymphatics in the portal tracts. For the purpose of this study a portal tract was defined as a structure having at least two of the following three structures: a portal vein or venule, a hepatic artery or arteriole, and a bile duct or ductule.

\section{Results}

Oesophageal varices were demonstrated in 50 patients $(47 \%)$. In the majority of these portal hypertension had been suspected either because they bled from the gastrointestinal tract (32 patients) or because of the presence of ascites and splenomegaly (12 patients). The patients with varices invariably had an enlarged spleen and 41 had ascites. None of the remaining subjects had both ascites and splenomegaly, and varices were not found. In 43 patients splenomegaly alone was present. The sex and age distribution, duration of symptoms before diagnosis of primary biliary cirrhosis, and total length of follow up was the same in the patients with and without varices (Table I). The biochemical findings in the two groups of patients are shown in Table I; the differences are not statistically significant. The mean duration of symptoms of primary biliary cirrhosis before the diagnosis of portal hypertension was made was 47.4 months (range $0-120$ months) (Fig. 1). The initial complaint in three patients was bleeding from oesophageal varices and another presented initially with ascites, and splenomegaly and varices were found. None of these patients was obviously jaundiced and three did not experience pruritus during the early stages of the disease, and this may explain the unusual mode of presentation. In a further seven patients varices were demonstrated within 12 months of the first symptom of primary biliary cirrhosis and in another 10 during the second 12 months.

Twenty-seven $(54 \%)$ of the patients in whom varices were found have died, including 18 of the 32 who bled from varices. The mean duration of survival from the onset of symptoms of primary biliary cirrhosis was 76.7 months (range 7-163 months) and from the time that varices were found

\begin{tabular}{|c|c|c|c|c|c|c|c|c|c|c|}
\hline & \multirow[t]{2}{*}{ No. } & \multicolumn{2}{|c|}{ Sex } & \multirow{2}{*}{$\begin{array}{l}\text { Age } \\
(y r)\end{array}$} & \multirow{2}{*}{$\begin{array}{l}\text { Duration of Symptoms } \\
\text { before Diagnosis (mth) }\end{array}$} & \multirow{2}{*}{$\begin{array}{l}\text { Total Length } \\
\text { of Follow up } \\
\text { (mth) }\end{array}$} & \multirow{2}{*}{$\begin{array}{l}\text { Bilirubin } \\
(m g \%)\end{array}$} & \multirow{2}{*}{$\begin{array}{l}\text { Alkaline Phosphatase } \\
(K-A u)\end{array}$} & \multirow{2}{*}{$\begin{array}{l}\text { Cholesterol } \\
(\mathrm{mg} \%)\end{array}$} & \multirow{2}{*}{$\begin{array}{l}\text { Aspartate } \\
\text { Transaminase } \\
\text { (IU) }\end{array}$} \\
\hline & & $\bar{F}$ & $M$ & & & & & & & \\
\hline $\begin{array}{l}\text { With } \\
\text { varices }\end{array}$ & 50 & 47 & 3 & $\begin{array}{l}52 \cdot 8^{1} \\
(35-68)^{2}\end{array}$ & $\begin{array}{l}32.9 \\
(0-120)\end{array}$ & $\begin{array}{l}64 \cdot 8 \\
(1-195)\end{array}$ & $\begin{array}{l}12.5 \\
(0.5-60)\end{array}$ & $\begin{array}{l}66 \cdot 6 \\
(19-360)\end{array}$ & $\begin{array}{l}306 \\
(72-1,300)\end{array}$ & $\begin{array}{l}64 \\
(12-310)\end{array}$ \\
\hline $\begin{array}{l}\text { Without } \\
\text { varices }\end{array}$ & 59 & 53 & 6 & $\begin{array}{l}51 \cdot 1 \\
(29-81)\end{array}$ & $\begin{array}{l}27 \cdot 1 \\
(3-108)\end{array}$ & $\begin{array}{l}60 \cdot 7 \\
(7-162)\end{array}$ & $\begin{array}{l}10 \cdot 9 \\
(0.5-50)\end{array}$ & $\begin{array}{l}84 \cdot 8 \\
(19-346)\end{array}$ & $\begin{array}{l}355 \\
(160-1,120)\end{array}$ & $\begin{array}{l}64 \\
(13-170)\end{array}$ \\
\hline
\end{tabular}

Table I General characteristics and relevant biochemical findings in the patients with and without oesophageal varices

'Mean 'Range 


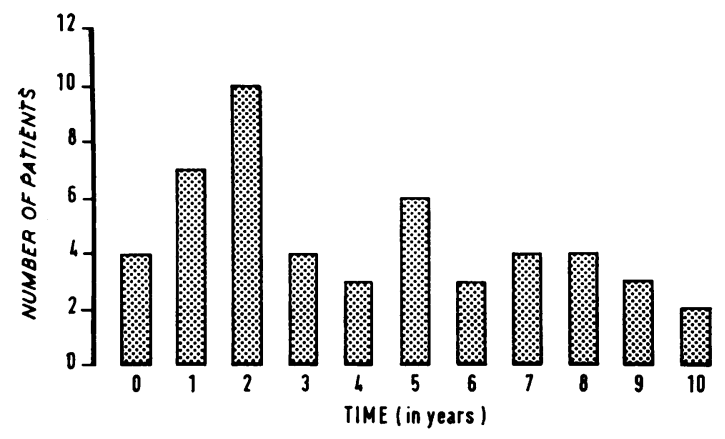

Fig. 1 The time elapsing between the first symptom of primary biliary cirrhosis and the recognition of portal hypertension.

14.9 months (range 0-71 months). Thirteen patients died from hepatic failure and one from a bleeding duodenal ulcer. In the remaining subjects death could be attributed directly or indirectly to bleeding from varices. Of the 59 patients in whom varices were not demonstrated, $12(20 \%)$ have died from hepatic failure during a period of follow up similar to that in the group with varices; the mean duration of survival from the onset of symptoms was 74 months (range 7-129 months). Another two patients died from causes unrelated to primary biliary cirrhosis (antibiotic-induced agranulocytosis and postoperative cardiac arrest in one each).

Portocaval anastomoses were performed in 11 patients; two died postoperatively and two following variceal haemorrhage when the anastomosis subsequently blocked. A fifth died from hepatic failure 72 months after the operation. The remaining patients are alive from one to 120 months (mean 37 months) after the operation. The mean duration of survival or follow up from the onset of symptoms in all of the patients in whom a portocaval anastomosis was performed was 72 months (range 1-195 months), compared with a mean figure of 58.5 months (range 4-120 months) in those who bled as a consequence of portal hypertension but were not operated upon.
Oesophageal or gastric transection was performed as an emergency procedure in three patients. One died postoperatively, the second during a subsequent variceal bleed, and the third as the result of a bleeding duodenal ulcer. In one patient oesophageal varices were ligated. She was well when seen four months later. Of the four patients in whom portal hypertension was the initial presentation, two had a portocaval shunt performed and oesophageal varices were ligated in one. These patients were alive when last seen four, 68, and four months after the operation respectively. The final patient was alive 57 months after initial presentation when she was lost to follow up. In two of the subjects with portal hypertension, portal vein thrombosis was found at the time of operation.

\section{Histological Findings}

The main findings are summarized in Table II. Hyperplastic ('regenerative') nodules characteristic of cirrhosis were significantly more common in the patients with varices than in the control group ( $P<0.02$ on a $\chi^{2}$ test). Marked portal fibrosis without nodules was equally common in the patients with and without varices and the degree of portal fibrosis was not significantly different in the two groups. The mean number of thin-walled vessels and arterioles in the portal tracts of the patients with varices was not significantly different from those in the control group. The degree of cellular infiltration of the portal zones and septa, thickness of the arteriolar walls, sinusoidal size, and number and size of efferent veins were similar in the two groups. Consistent twin-hepatocyte plates were only marginally more common in the patients with varices than in those without varices. If only the patients without nodules were considered, six out of 10 with varices had consistent twin-hepatocyte plates compared with six out of 16 in the control group. Lymphoid aggregates were present in all but two of the cases with and three without varices. Mononuclear cells were present in all but one case in each group and Kupffer cells were prominent or hyperplastic in only two patients with and three without varices.

\begin{tabular}{|c|c|c|c|c|c|c|c|c|c|c|c|c|c|c|c|}
\hline & \multirow[t]{2}{*}{ Nodules } & \multicolumn{2}{|l|}{ Fibrosis } & \multicolumn{2}{|c|}{$\begin{array}{l}\text { Thin-walled } \\
\text { Vessels }\end{array}$} & \multicolumn{2}{|c|}{$\begin{array}{l}\text { Number of } \\
\text { Arterioles }\end{array}$} & \multicolumn{4}{|c|}{ Sinusoids } & \multirow{2}{*}{$\begin{array}{l}\text { Consistent } \\
\text { Twin-hepatocyte } \\
\text { Plates }\end{array}$} & \multicolumn{3}{|c|}{$\begin{array}{l}\text { Central Veins } \\
\text { Number }\end{array}$} \\
\hline & & Marked & Slight & Mean & Range & Mean & Range & $N^{1}$ & $P C^{2}$ & $P D^{2}$ & $P D$ & & Norm & & \\
\hline Varices & $15(58 \%)$ & $\stackrel{9}{(35 \%)}$ & $\begin{array}{l}2 \\
(7 \%)\end{array}$ & 7.9 & $\begin{array}{l}3 \cdot 3- \\
17\end{array}$ & $2 \cdot 4$ & $\begin{array}{l}1.4- \\
4.4\end{array}$ & 12 & 3 & 4 & 3 & $13(56 \%)$ & 15 & 9 & 1 \\
\hline No varices & $5(24 \%)$ & $\begin{array}{l}11 \\
(52 \%)\end{array}$ & $\begin{array}{l}5 \\
(24 \%)\end{array}$ & $6 \cdot 3$ & $\begin{array}{l}3.4 \\
10 \cdot 6\end{array}$ & $2 \cdot 2$ & $\begin{array}{l}0 \cdot 8- \\
4 \cdot 0\end{array}$ & 10 & 5 & 3 & 2 & $8(38 \%)$ & 12 & 7 & 1 \\
\hline
\end{tabular}

Table II Correlation between the main histological findings and the presence or absence of oesophageal varices

'Normal 'Patchy constriction 'Patchy dilatation 
The four patients in whom portal hypertension was the initial manifestation of primary biliary cirrhosis all showed nodular regeneration of the liver at the time of presentation. Of the other 17 patients in whom portal hypertension developed within two years of the first symptom of primary biliary cirrhosis, 10 had regenerative nodules. In five patients two wedge biopsies or one wedge biopsy and necropsy material were available for study. None showed clinical or radiological evidence of portal hypertension at the time of the first biopsy but by the time of re-examination four patients had developed this complication. Regenerative nodules had developed in two of these patients but apart from this there were no differences between the early and late biopsies. The two patients in whom portal vein thrombosis was found at operation both had nodular regeneration of the liver.

\section{Discussion}

This study has confirmed that portal hypertension is neither an infrequent nor always a late occurrence in primary biliary cirrhosis. Clinical and radiological evidence of this complication was found in nearly one-half of the patients and the majority of these bled from oesophageal varices. Many of the remaining subjects had an enlarged spleen and some of these undoubtedly had early or mild portal hypertension. However, we did not feel justified in measuring intrasplenic pressures in patients of this sort because of the danger of bleeding from the splenic puncture site.

Although bleeding from varices may be the presenting feature in patients with primary biliary cirrhosis, as shown by Zeegen et al (1969), this mode of presentation was not common. The 23 cases reported by Zeegen et al (1969) were found amongst 250 patients with chronic liver disease who required portal decompression operations and they therefore constitute a highly selected group. Nevertheless, the observation that portal hypertension may manifest early in the clinically recognizable course of the disease is confirmed by the fact that in $40 \%$ of the subjects in whom this sequence of events occurred, it did so within two years of the first symptom of primary biliary cirrhosis. In the four patients who presented in the first instance with complications of portal hypertension, the clinical features were atypical in that neither pruritus nor jaundice were prominent during the early stages of the disease, and this may explain the unusual mode of presentation.

The overall prognosis of the patients in this series was similar to that found in a previous study (Sherlock, 1959). However, the outlook was very much worse in those in whom varices were demonstrated. The number of patients who died from hepatic failure was similar in the two groups with and without varices so that the excess mortality in the subjects with varices could be attributed directly or indirectly to bleeding from oesophageal varices. Although successful decompression of the portal venous system may have improved the immediate prognosis in individual patients, the overall progression of the disease was not altered.

There are several possible mechanisms of obstruction to the portal venous system in primary biliary cirrhosis. In those patients in whom nodular regeneration of the liver is present, the pathogenesis of portal hypertension is presumably the same as that which has been postulated for the more common forms of hepatic cirrhosis, and we have been able to confirm an association between the presence of regenerating nodules and the finding of oesophageal varices. However, portal hypertension may antedate the appearance of nodules in primary biliary cirrhosis (Sherlock, 1959; Hoffbauer, 1960; Zeegen et al, 1969; Sicot and Benhamou, 1970), and in this study nearly one-half of the patients with varices fell into this category. In this situation Zeegen et al (1969) have postulated that obstruction to portal venous flow may occur at a presinusoidal level and be caused by the portal tract lesions. It has also been suggested by Hoffbauer (1960) that the small vessels in the portal tracts may be obliterated and destroyed in this disease in much the same way as the interlobular bile ducts (Baggenstoss, Foulk, Butt, and Bahn, 1964). However, in the present study marked or moderate portal fibrosis was no more common in the patients with varices, and there was no difference in other factors, such as cellular infiltration or lymphoid aggregates in the portal tracts or septa, which might have caused obstruction at a presinusoidal level. There was also no difference in the number of thin-walled vessels (venous and lymphatic) or arterioles in the portal tracts of the patients with and without varices. Nor could definite evidence of obstruction of efferent veins, or at a sinusoidal level by mononuclear cell infiltration, hyperplasia or hypertrophy of Kupffer cells, or narrowing of sinusoids by consistent twin-hepatocyte plates be demonstrated. Thus, in the absence of nodular regeneration, we were unable to find an alternative explanation for portal hypertension although the slight possibility exists that haemodynamically significant nodules had formed in parts of the liver remote from the biopsy site (Hadziyannis, Scheuer, Feizi, Naccarato, Doniach, and Sherlock, 1970). Understanding of the pathogenesis of portal venous obstruction was further complicated by the fact that regenerating nodules were present in one-third of 
the patients without oesophageal varices and by the finding of portal vein thrombosis in two of the hypertensive patients.

\section{References}

Baggenstoss, A. H., Foulk, W. T., Butt,H. R., and Bahn, R. C. (1964). The pathology of primary biliary cirrhosis with emphasis on histogenesis. Amer. J. clin. Path., 42, 259-276.

Hadziyannis, S., Scheuer, P. J., Feizi, T., Naccarato, R., Doniach, D., and Sherlock, S. (1970). Immunological and histological studies in primary biliary cirrhosis. J. clin. Path., 23, 95-98.
Hoffbauer, F. W. (1960). Primary biliary cirrhosis. Observations on the natural course of the disease in 25 women. Amer. J. dig. Dis., 5, 348-383.

Rubin, E., Schaffner, F., and Popper, H. (1965). Primary biliary cirrhosis. Chronic non-suppurative destructive cholangitis. Amer. J. Path., 46, 387-407.

Sherlock, S. (1959). Primary biliary cirrhosis. (Chronic intrahepatic obstructive jaundice.) Gastroenterology, 37, 574-586.

Sicot, C., and Benhamou, J. P. (1970). Portal hypertension and primary biliary cirrhosis. In Proceedings Fifth Meeting European Association for the Study of the Liver, pp. 25-26.

Zeegen, R., Stansfeld, A. G., Dawson, A. M., and Hunt, A. H. (1969). Bleeding oesophageal varices as the presenting feature in primary biliary cirrhosis. Lancet, 2, 9-13.

\section{The September 1971 Issue}

\section{THE SEPTEMBER 1971 ISSUE CONTAINS THE FOLLOWING PAPERS}

Bacteria, bile salts, and intestinal monosaccharide malabsorption MICHAFL GRACEY, VALERIE BURKE, ADEMOLA OSHIN, JUDITH BARKER, AND ERIC F. GLASGOW

An ultrastructural study of the liver in Indian childhood cirrhosis with particular reference to the structure of cytoplasmic hyaline s. ROY, v. RAMALINGASWAMI, AND N. C. NAYAK

Effect of lactulose on cerebral metabolism in patients with chronic portosystemic encephalopathy I. M. JAMES AND M. GARASSINI

Jaundice due to iprindole A. B. AJDUKIEWICZ, J. GRAINGER, P. J. SCHEUER, AND S. SHERLOCK

Small bowel in typhoid fever H. K. CHUTTANI, K. JAIN, AND R. C. MISRA

Influence of diet on flatus volume in human subjects P. J. DAVIES

Further studies on streptozotocin therapy for a multiple-hormone-producing islet cell carcinoma IAIN M. MURRAY-LYON, J. CASSAR, R. COULSON, ROGER WILliams, P. C. GANGULI, J. C. EDWARDS, AND KEITH W. TAYLOR
Further observations concerning the effects of hypophysectomy on the gastric mucosa of the rat G. P. CREAN, R. D. E. RUMSEY, AND SYLVIA M. WHEELER

A comparison between spectrophotometric and titrimetric methods of estimatıng trypsin H. SACKS, S. BANK, I. KRAMER, B. NOVIS, AND I. N. MARKS

Clinical evaluation of fibreoptic sigmoidoscopy employing the Olympus CF-SB colonoscope P. R. SALMON, R. A. BRANCH, C. COLLINS, H. ESPINER, AND A. E. READ

A comparative study of conventional premedication (pethidine, promethazine, and atropine) and neuroleptanalgesia (droperidol and phenoperidine) for peroral endoscopy W. D. REED, B. E. HOPKINS, R. A. JOSKE, AND B. H. LAURENCE

Progress report The place of surgery in Crohn's disease J. ALEXANDER WILLIAMS

Progress report Acute haemorrhagic gastritis: Modern concepts based on pathogenesis KEVIN J. IVEY

\section{Notes and activities}

Copies are still available and may be obtained from the PUBLISHING MANAGER, BRITISH MEDICAL ASSOCIATION, TAVISTOCK SQUARE, LONDON, WC1H 9JR, price $87 \frac{1}{2} \mathrm{p}$ 